\title{
Violência contra a Mulher e Representações Mentais: Um Estudo sobre Pensamentos Morais e Sentimentos de Adolescentes
}

\author{
Valéria Amorim Arantes ${ }^{1}$ \\ Universidade de São Paulo \\ Genoveva Sastre \\ Alba González \\ Universidade de Barcelona (Espanha)
}

\begin{abstract}
RESUMO - Nesta pesquisa analisamos processos psicológicos subjacentes às formas de situar-se diante da violência contra a mulher. Participaram 120 adolescentes brasileiros, estudantes de escolas públicas da cidade de São Paulo, de ambos sexos, com 12, 14 e 16 anos. O instrumento consistiu no relato de um conflito com episódios de violência física e verbal vivido por uma adolescente e seu namorado. Identificamos cinco maneiras de posicionar-se diante da violência contra a mulher e uma relação entre as estratégias de resolução propostas, os pensamentos e sentimentos atribuídos aos protagonistas e a dinâmica imaginada para essa relação. Foi observado que a violência se dá mais entre os homens do que entre as mulheres, e mais entre os mais novos do que entre os mais velhos.
\end{abstract}

Palavras-chave: violência contra a mulher; representações mentais; modelos organizadores do pensamento; adolescência.

\section{Violence against Women and Mental Representations: A Study about Moral Thoughts and Feelings of Adolescents}

\begin{abstract}
In this research we analyzed the psychological processes underlying some forms of facing violence against women. The participants were 120 Brazilian adolescents from public schools of São Paulo, of both genders, and aged 12 , 14 and 16 years old. The instrument was a report of a conflict with episodes of verbal and physical violence experienced by an adolescent and her boyfriend. We identified five different ways to understand the violence against women and a relation among the proposed resolutions' strategies, thoughts and feelings attributed to the protagonists, and the imagined dynamics for this relation. It was observed that violence occurs more among men than among women, and more among younger than among older people.
\end{abstract}

Keywords: violence against women; mental representations; thoughts organizing models; adolescence.

A violência contra a mulher, como postula Lima, Buchele e Clímaco (2008), consiste em um grave problema de saúde pública e violação dos direitos humanos. Além de acarretar graves consequências para o desenvolvimento pleno e integral da mulher, compromete o desenvolvimento socioeconômico do país (Narvaz \& Koller, 2006a). Nesse sentido, a violência contra a mulher não pode ser encarada como uma questão da vida privada, mas sim objeto de preocupação social (Bravo, 1994).

A complexidade que envolve a problemática da violência contra a mulher - que abarca as formas de violência física, violência sexual e violência emocional ou psicológica (Corsi, 1997, 2003) -, requer estudos e intervenções sob diferentes perspectivas. Conscientes das diversas dimensões - sociais, políticas, econômicas etc. - que envolvem a referida temática, o presente trabalho está circunscrito no campo psicológico e tem como propósito analisar as representações mentais de adolescentes sobre um episódio de violência - física e psíquica - sofrida por uma mulher, colocando em evidência os fatores psicológicos subjacentes a essas representações.

1 Endereço para correspondência: Faculdade de Educação, Universidade de São Paulo. Av. da Universidade, 308, Cidade Universitária. São Paulo, SP. CEP 05.508-900.Email: varantes@usp.br.
Tais fatores contribuem para a compreensão das diferentes maneiras de situar-se diante da violência contra a mulher - aceitá-la, negá-la ou lutar contra ela, entre outras. Isso porquê, se no plano social a discriminação das mulheres é, claramente, uma violação dos direitos humanos (Lei $\mathrm{N}^{\circ}$. 11.340, de 07 de Agosto de 2006), do ponto de vista psicológico contempla vínculos afetivos que exercem importante papel na construção de relações entre homens e mulheres dentro de uma estrutura de submissão e domínio. Uma violência que surge da tentativa frustrada de dominação (Giddens, 1993).

Sastre, Arantes e González (2007) evidenciaram que a grande maioria das adolescentes não está preparada para identificar e opor-se ao maltrato causado por seus parceiros. Tal fato parece sinalizar a necessidade de se criar e implantar programas de prevenção e, para tanto, faz-se fundamental conhecer as formas de opressão a que as mulheres e as meninas de nossa sociedade têm sido submetidas (Narvaz \& Koller, 2006b). Isso requer, entre outras coisas, estudos sobre os mecanismos psíquicos que influenciam tal fenômeno, em especial com a população jovem, já que o período em que se iniciam as primeiras relações é um momento crítico para o trabalho preventivo. No Brasil há alguns estudos recentes e relevantes sobre a violência contra a mulher com jovens (Affonso, 2008; Machado, 2004; Martins, 2008; Nascimento, 
2004; Taquete, Ruzany, Meirelles \& Ricardo, 2003; TraversoYépez \& Pinheiro, 2005).

No campo da psicologia, aqueles estudos que buscam pelo continuum entre as vertentes social e individual da violência de gênero têm ganhado cada vez mais força, tanto nas pesquisas como na área clínica. Uma síntese dos trabalhos mais recentes que buscam identificar e analisar os diferentes caminhos pelos quais o social transforma-se em psiquismo pode ser encontrada em Ferrer e Bosch (2003).

Velázquez (2003), a partir de práticas terapêuticas, aponta que o exercício de poder no contexto de uma relação leva a abusos e conflitos que, além de provocarem a submissão de uma das partes, dão origem a vários circuitos de violência. Segundo essa autora, mulheres e homens "podem ser objeto e sujeito de violência, embora a situação de subordinação social da mulher favoreça que esta se transforme, com maior frequência, em destinatária de violências estruturais e conjunturais." (p. 24, tradução livre).

Nessa mesma direção, a psicanalista Benjamín (1996, 1997) assinala que as estruturas sociais genéricas estão no cerne daquelas relações pessoais nas quais se exerce abuso de poder. Assinala, ainda, que a violência contra a mulher se dá numa estrutura interativa de domínio abusivo que pretende despojar a mulher de sua identidade. Uma relação de domínio que se nutre do mesmo desejo de reconhecimento que encontramos no sentimento de amor (Benjamín, 1996). Mas, por que o reconhecimento do outro nos conduziria a uma relação de submissão e não de igualdade? Estaria a violência contra a mulher sustentada numa estrutura afetiva em que uma das partes assume o papel de sujeito dominante, enquanto a outra se submete, por amor, aos seus desejos? Tais questões foram pontos de partida para o presente trabalho.

Para respondê-las, buscamos um enfoque teórico que nos permitisse abordar a identidade das mulheres, considerando os princípios éticos transgredidos na violência contra ela. Escolhemos, pois, os estudos de Benhabib (1992), pela relação que a autora estabelece entre identidade, ética e direitos humanos. Segundo a autora,

alcançamos um sentido coerente com a própria identidade quando integramos com êxito autonomia e solidariedade, quando combinamos adequadamente justiça e cuidado. A justiça e a autonomia por si só não podem sustentar nem alimentar este tecido narrativo no qual se desenvolve o sentido de identidade dos seres humanos, mas também a solidaridade e o cuidado por si só podem levar o sujeito a não ser tão somente sujeito, mas também o autor de um relato coerente da própria vida. (p. 59, tradução livre)

A partir do exposto nas palavras de Benhabib (1992), podemos entender que a prevenção da violência contra as mulheres supõe, entre outras coisas, a construção de uma identidade que integra autonomia e solidariedade, bem como integra justiça e cuidado. Se tal suposição for correta, cabem duas indagações. Primeira: nossa cultura realmente favorece a construção, por parte das mulheres, da virtude solidariedade em detrimento da justiça? Segunda: até que ponto essa mesma cultura não contribui para que os homens construam sua autonomia à custa da solidariedade femini- na? Dito de outra forma, faz-se fundamental indagar se, tal como postulou Gilligan (1982), temos duas vias diferentes de construção de valores e da moralidade humana: uma para os homens, centrada na autonomia/justiça; e outra para as mulheres, centrada na solidariedade/cuidado. Por fim, cabe indagar, também, sobre as possíveis implicações de uma via sobre a outra nas relações e conflitos de gênero. Essas indagações levaram-nos a considerar que o desenvolvimento anômalo da primeira via - autonomia/justiça - pode levar os homens à solidão e ao narcisismo; e que o desenvolvimento anômalo da segunda via - solidariedade/ cuidado - pode levar as mulheres à perda do controle da própria existência.

Segundo Busch e Folger (1994), a resolução de conflitos permite dar uma importância similar ao processo e produto final, bem como favorece a compreensão de cada uma das partes nele envolvidas. As situações de conflitos constituemse, assim, uma perspectiva privilegiada para pensarmos a complexa trama tecida pela diversidade e subjetividade de fatores que se entrelaçam nas relações humanas. Sua resolução exige que descentremos do próprio ponto de vista para contemplarmos, simultaneamente, outros pontos de vista diferentes e, muitas vezes, opostos aos nossos. Exige-nos, ainda, a elaboração de fusões criativas entre os diferentes pontos de vista. Tal processo implica, necessariamente, operações de reciprocidade e síntese entre as diferenças. Uma análise, pois, emocional e cognitiva.

Trilhando esse caminho, para o presente estudo concedemos especial atenção aos pressupostos que Del Barrio, Almeida, Van der Meulen, Barrios e Gutiérrez (2003) adotaram em suas pesquisas para identificação do maltrato, das estratégias utilizadas para a resolução do conflito em questão, bem como dos padrões de atribuição emocional para cada um dos protagonistas nele envolvidos. Tais padrões parecem-nos especialmente importantes, na medida em que o estabelecimento de vínculos afetivos é um processo interativo e dinâmico que não pode ser descrito com base em partes isoladas. Cada individuo, em função de sua história pessoal, de suas experiências afetivas e dos valores de seu entorno cultural, vai desempenhando aqueles papéis que julga pertinentes no cenário de cada nova relação (Noam \& Fischer, 1996). Somado a tais pressupostos, assumimos como referencial teórico-metodológico a teoria dos Modelos Organizadores do Pensamento, estruturada por Marimón, Sastre, Bovet e Leal (1988/2000) e que nos permitiu realizar uma análise qualitativa da opinião de cada um dos participantes do presente estudo, respeitando sua idiossincrasia e, ao mesmo tempo, detectando suas semelhanças e diferenças.

Partindo da ideia de que o sujeito constrói modelos da realidade que lhe permite conhecer uma parte do mundo que o cerca, a teoria dos Modelos Organizadores do Pensamento procura estudar a forma como ele os constrói. Frente a acontecimentos “observáveis", por meio dos quais é possível realizar diversas interpretações, cada sujeito seleciona e organiza uma série de elementos e significados, a partir dos quais constrói um modelo organizador. Nesse sentido, tal referencial confere uma maior fidedignidade aos dados, uma vez que não trabalha com categorias pré-determinadas de modelos organizadores. Eles são extraídos das respostas dos sujeitos e não por inferências prévias do(a) pesquisador(a). 
Tabela 1. Distribuição dos participantes por sexo e idade.

\begin{tabular}{ccccc}
\hline Idade & Mulheres & Homens & Total \\
\hline 12 anos & 20 & 20 & 20 \\
14 anos & 20 & 20 \\
16 anos & 20 & 40 \\
Total & 60 & 60 \\
\hline
\end{tabular}

Com isso temos uma maior visibilidade da diversidade dos modelos elaborados pelos sujeitos.

No entanto, a despeito dos diferentes pontos de vista sobre um mesmo fato, a possibilidade de ordenamento dos elementos que compõem o modelo organizador - cuja função está em dar coerência interna a eles - não é infinita, posto que possuem certo grau de compatibilidade com o "real" (Marimón \& cols., 1988/2000). A teoria dos Modelos Organizadores do Pensamento assume, assim, a importância da experiência como elemento regulador do psiquismo humano.

Por fim, vale ressaltar que, apesar de serem contingentes com a lógica subjacente às estruturas de pensamento, os Modelos Organizadores não são construídos somente a partir delas. Eles ampliam a análise ao incluir desejos, sentimentos, afetos, representações sociais e valores de quem os aplicam. Nesse sentido, tal referencial abre-nos possibilidades para um entendimento mais amplo sobre as estratégias utilizadas pela mente humana na resolução de conflitos, demonstrando como diferentes aspectos - afetivos, cognitivos e sociais - articulam-se de maneira dialética no funcionamento psíquico.

O presente estudo, de caráter qualitativo e exploratório, teve como principal objetivo identificar e analisar os processos psicológicos subjacentes às diferentes formas de situar-se diante da violência contra a mulher. Mais especificamente, tal objetivo foi concretizado da seguinte forma: (a) identificando as diferentes estratégias de resolução do conflito que retrata tal violência; (b) identificando os vínculos cognitivos/ afetivos projetados na relação entre os protagonistas; (c) relacionando as estratégias de resolução do conflito com os vínculos afetivos projetados na referida relação.

\section{Método}

\section{Participantes}

Participaram deste estudo 120 adolescentes brasileiros, estudantes de escolas públicas situadas na periferia da região sul da cidade de São Paulo, de nível socioeconômico baixo ${ }^{2}$, mulheres e homens, de 12, 14 e 16 anos, conforme mostra a Tabela 1.

2 O IDH - Indice de Desenvolvimento Humano - da referida região é de 0.400. O IDH da cidade de São Paulo é de 0.841 e do Brasil é de 0.807 .

\section{Instrumento}

O instrumento utilizado no presente estudo visou, entre outras coisas, explorar as representações de vínculos que unem o homem e a mulher, contribuindo para a identificação e análise das projeções que, numa situação de violência, realizam-se sobre ambos. Tal instrumento foi criado a partir do texto escrito por uma adolescente, referente a um conflito interpessoal por ela vivido ${ }^{3}$. Com base nesse texto, elaboramos uma situação na qual a adolescente relatava aspectos de sua vida - seus estudos, suas relações com a família, com o namorado e com os amigos -, bem como um conflito vivido entre ela e seu namorado, que compreendia episódios de violência física e insultos. O referido instrumento não apresenta nenhuma valoração de ordem moral e os participantes são indagados sobre que conselho dariam à protagonista da história e o que fariam se estivessem numa situação semelhante àquela, além de serem solicitados a tentar se colocar no lugar dos personagens e imaginar seus pensamentos e sentimentos. Tais procedimentos se deram por acreditarmos que essas demandas abertas, sem referência explícita ao raciocínio moral, evitam respostas "politicamente corretas" e revelam os princípios com os quais julgamos as condutas humanas.

\section{Procedimento}

A coleta de dados foi realizada com os grupos organizados por idade. Inicialmente foram passados para os participantes esclarecimentos sobre o anonimato e sigilo. Foi garantido o caráter voluntário da participação, bem como o respeito às diretrizes éticas que regem a pesquisa com seres humanos, conforme Resolução no 196/96 do Conselho Nacional de Saúde. Após dar oportunidade para aqueles que não quisessem responder ao instrumento da pesquisa se retirarem da sala de aula, demos início à aplicação do mesmo.

Para garantir a compreensão de todos os participantes, entregamos uma cópia do texto para cada um deles, fizemos sua

3 O texto completo, já utilizado em estudo anterior (Sastre, Arantes e González, 2007), encontra-se no Apêndice. Enquanto no texto original (em espanhol) os protagonistas receberam os nomes de Juan e Laura, no Brasil receberam os nomes de Bruno e Laura. 
Tabela 2. Categorias de resolução do conflito.

\begin{tabular}{|c|c|c|}
\hline CATEGORIAS & DEFINIÇÕES & EXEMPLOS \\
\hline Ruptura & A ruptura imediata da relação. & Separar-se de Bruno porque ele a maltrata. \\
\hline Possível Ruptura & $\begin{array}{l}\text { A ruptura após se dar uma oportunidade ao } \\
\text { agressor para que ele mude; }\end{array}$ & $\begin{array}{l}\text { Conversar com ele e se não adiantar, terminar } \\
\text { tudo. }\end{array}$ \\
\hline Diálogo & $\begin{array}{l}\text { O diálogo como forma de resolver o confli- } \\
\text { to; não sinaliza nenhuma possibilidade de } \\
\text { ruptura. }\end{array}$ & $\begin{array}{l}\text { Conversar com Bruno sobre o que aconteceu, } \\
\text { pois numa relação o diálogo e a sinceridade } \\
\text { são muito importantes. }\end{array}$ \\
\hline Resignação & $\begin{array}{l}\text { Aceitação da situação sem apresentar nenhu- } \\
\text { ma ação. }\end{array}$ & Esperaria para ver o que acontece. \\
\hline Interesse Agressor & $\begin{array}{l}\text { Defende os interesses do agressor e/ou propõe } \\
\text { ajudá-lo. }\end{array}$ & Tentaria ajudá-lo com calma e dedicação. \\
\hline
\end{tabular}

leitura em voz alta e esclarecemos as dúvidas que surgiram. Comentamos, também, que existem diferentes maneiras de se resolver um mesmo conflito e que todas elas têm vantagens e inconvenientes. Enfatizamos nosso interesse pelas ideias de todos eles, entregamos cada uma das perguntas separadamente (a fim de garantir que eles não tivessem acesso à questão subsequente antes de responderem à antecedente), e solicitamos que respondessem individualmente e que explicassem detalhadamente suas respostas. Para garantir o anonimato pedimos aos participantes que criassem um pseudônimo.

As perguntas apresentadas aos participantes foram:

(1) Explique detalhadamente o que você faria se fosse amiga(o) de Laura e ela lhe perguntasse o que fazer diante da situação enfrentada.

(2) O que você faria se estivesse numa situação parecida à de Laura?

(3) O que você acha que Bruno está pensando?

(4) O que você acha que Laura está pensando?

(5) O que você acha que Bruno está sentindo?

(6) O que você acha que Laura está sentindo?

\section{Resultados}

Para elaboração dos modelos organizadores correspondentes às respostas dos participantes seguimos os passos descritos a seguir.

\section{$1^{\circ}$ Passo: Categorias de análise}

Analisamos cada uma das perguntas separadamente, bem como aqueles elementos que os participantes consideraram relevantes e seus respectivos significados. Essa primeira análise permitiu-nos elaborar quatro classes de categorias, que organizamos em quatro diferentes tabelas (Tabelas 2, 3, 4 e 5).

A Tabela 2 sintetiza a caracterização das estratégias de resolução propostas pelos participantes ao responderem à primeira e à segunda questões ("Explique detalhadamente o que você faria se fosse amiga(o) de Laura e ela lhe perguntasse o que fazer diante da situação enfrentada" e "O que você faria se estivesse numa situação parecida à de Laura?", respectivamente). A primeira coluna da tabela traz os nomes das cinco categorias elaboradas a partir das estratégias propostas pelos participantes; a segunda coluna traz a definição de cada uma dessas categorias; a terceira coluna traz exemplos de cada uma delas.

,Nas duas tabelas que se seguem estão aquelas categorias referentes aos pensamentos atribuídos ao agressor (Tabela 3) e à vitima (Tabela 4), obtidas a partir das respostas obtidas na terceira e quarta questões ("O que você acha que Bruno está pensando?" e "O que você acha que Laura está pensando?", respectivamente). Na primeira coluna constam as categorias elaboradas a partir das análises apresentadas pelos participantes; na segunda coluna, a definição de cada uma dessas categorias; e na terceira coluna, exemplos dessas categorias.

A Tabela 5 ilustra os sentimentos atribuídos a ambos os protagonistas do conflito, quando os participantes responderam à quinta e à sexta questões ("O que você acha que Bruno está sentindo?" e "O que você acha que Laura está sentindo?", respectivamente). A primeira coluna traz os nomes das categorias elaboradas a partir dos sentimentos atribuídos pelos participantes; a segunda coluna traz a definição de cada uma dessas categorias; e a terceira coluna traz exemplos de cada uma delas.

\section{$2^{\circ}$ Passo: Elaboração dos modelos organizadores do pensamento}

Considerando as categorias apresentadas nas quatro tabelas anteriores, realizamos uma análise intrapessoal, ou seja, analisamos todos as respostas de cada um dos participantes separadamente, o que nos permitiu identificar que para cada forma de abordar o conflito temos uma determinada dinâmica entre o casal. Aqueles participantes que sugeriram a ruptura como forma de resolver o conflito imaginaram uma relação 
Tabela 3. Categorias de pensamentos atribuídos ao agressor.

\begin{tabular}{lll}
\hline \multicolumn{1}{c}{ CATEGORIAS } & \multicolumn{1}{c}{ DEFINIÇÕES } & EXEMPLOS \\
\hline Minimiza / Nega o Problema & Não identifica o problema ou naturaliza-o. & $\begin{array}{l}\text { Ele pensa que a situação é normal e que as } \\
\text { discussões são coisas que acontecem e depois } \\
\text { passam. }\end{array}$ \\
\hline Problemática do Professor & $\begin{array}{l}\text { Centra-se na problemática interna do agressor e } \\
\text { sugere que ele mudará ou reparará a situação. }\end{array}$ & $\begin{array}{l}\text { Bruno pensa que é inseguro e que tem proble- } \\
\text { mas. }\end{array}$ \\
\hline Valoração Negativa da Vítima & $\begin{array}{l}\text { Valoração negativa da vítima, quer seja porque } \\
\text { ele não se importa com ela, quer seja porque } \\
\text { Bruno acredita que a causadora do problema } \\
\text { foi ela. }\end{array}$ & $\begin{array}{l}\text { Nada! Pensa que sua namorada é uma boba, } \\
\text { pois depois de tudo o que ele fez...Laura não } \\
\text { fez nada para evitar a situação. }\end{array}$ \\
\hline Assume sua Violência & $\begin{array}{l}\text { Refere-se ao seu comportamento como estraté- } \\
\text { gia para controlar e/ou dominar a relação ou se } \\
\text { autoafirmar. }\end{array}$ & $\begin{array}{l}\text { Bruno pensa que ele tem que ter o domínio da } \\
\text { situação. }\end{array}$ \\
\hline
\end{tabular}

de oposição/confronto entre os protagonistas, enquanto aqueles que sugeriram manter a relação projetaram relações de complementaridade. Os níveis de submissão/domínio encontrados em cada uma das dinâmicas variaram em função da estratégia de resolução proposta.

No total, identificamos cinco diferentes modelos organizadores do pensamento, que refletem maneiras e níveis distintos de tratar a violência contra a mulher, de posicionarse diante dela. Cada um desses modelos (Modelos 1, 2, 3, 4 e 5) foram nomeados, respectivamente, de: maltrato e ruptura; desavenças e possível ruptura; diálogo e manter a relação; aceitação silenciosa e manter a relação; interesse do agressor e manter a relação. Em função do tipo de análise realizada (com grande quantidade de informações para cada um desses modelos), e pelo pouco espaço disponível em um artigo, deter-nos-emos na descrição do primeiro e último deles (Modelos 1 e 5), e limitar-nos-emos a uma breve caracterização dos Modelos 2, 3 e 4, considerando que o(a) leitor(a) não terá dificuldades para compreendê-los. Tal escolha deveu-se ao fato de que os Modelos 1 e 5 não só apresentam um antagonismo no que se refere às estratégias de resolução - enquanto o primeiro modelo sugere a ruptura, o último propõe a manutenção da relação -, como também apresentam diferenças substantivas no que tange a atribuição de pensamentos e sentimentos à vitima e ao agressor. Dito de outra forma, os Modelos 1 e 5 são aqueles que, quando comparados, apresentam maior discrepância entre os elementos abstraídos e retidos como significativos, os significados atribuídos a tais elementos e as relações e/ou implicações estabelecidas entre eles.

\section{Modelo 1: maltrato e ruptura}

Estratégia de resolução. O elemento organizador desse modelo é o comportamento violento de Bruno, que recebe o significado de maltrato. Nesse modelo, a violência é, portanto, reconhecida explicitamente. Os demais elementos presentes no conflito ou não foram considerados pelos participantes ou lhes foram outorgados papéis secundários, o que não significa, por exemplo, que os afetos tenham sido desprezados, mas que eles ocuparam um papel secundário

Tabela 4. Categorias de pensamentos atribuídos à vítima.

\section{CATEGORIAS DEFINIÇÕES}

\section{EXEMPLOS}

Acho que por mais de uma vez ela pensou em dei-

Ruptura Propõe deixar a relação. xar a relação com Bruno, já que está claro que ela não está satisfeita com ele.

Pensa que Bruno é uma pessoa egoísta e que sempre discordará dela.

$\begin{array}{ll}\text { Valoração Negativa } & \text { Valora negativamente a conduta de } \\ \text { do Agressor } & \text { seu companheiro. }\end{array}$

Ela está muito confusa e pode ter mais de dez mil pensamentos diferentes passando em sua cabeça. Algumas vezes ela deve pensar que Bruno está cansado dela e por isso faz essas coisas; que Bruno realmente tem um problema grave que afeta ela, a relação e ele próprio; talvez ela pense que ele é um rapaz inseguro e que aquela situação irá longe... 
Tabela 5. Categorias de sentimentos atribuídos ao agressor e à vítima.

\section{CATEGORIAS}

DEFINIÇÕES

\section{EXEMPLOS}

Eu acho que ela se sente doída pelo comportamento de Bruno.

Pena, desgosto, moléstia, dor, baixa autoestima etc.

Tristeza

Querer, querida/o, se amam, se gostam etc.

Eles se querem muito.
Sentir-se bem, alegre, contente, feliz etc.
Bruno sente-se bem porque ele quer fazer o que gosta e está indo no caminho certo.
Confusão

Desconcerto, bloqueio, perda etc.
Sente-se enrolada, não sabe o que fazer e sente que tem que deixar algo...aquilo que necessita menos.

Depois de agir como agiu, sente-se um pouco culpado. Já aconteceu isso comigo...depois de agir sem pensar, pensei comigo: Por que eu fiz isso?.

Deve ter se sentido enganada, muito decepcionada.
Decepção

Depressão

Culpado, responsável etc.

Engano, abandono, estafada, decepção, utilizada etc.

Um pouco abatida, sem saber o que fazer.

impotente etc.

\begin{tabular}{lll}
\hline Domínio & Dominante, poderoso, superior etc. & Dominador, ele gosta de controlar a situação. \\
\hline Incompreensão & $\begin{array}{l}\text { Isolada, sozinha, incompreendida, } \\
\text { ignorada etc. }\end{array}$ & $\begin{array}{l}\text { Ignorada, uma simples boneca para ter como namorada...usar } \\
\text { e depois depreciar. }\end{array}$
\end{tabular}

$\begin{array}{ll}\text { Indiferença } & \begin{array}{l}\text { Não dá importância à situação, indi- } \\ \text { ferente, tranquilo etc. }\end{array}\end{array}$

Indignação

Irritação, nojo, fúria, chateação etc.

Menosprezo, humilhação, inútil, rechaço etc.
Não importa com nada, ele ignora tudo. Bruno não deve pensar nada....mas tem maus pensamentos.

Sente-se pressionado por ela e tenta que ela lhe deixe em paz com o assunto da insegurança. Esse assunto deve ser tratado somente por ele.

Acho que se sente incomodado e humilhado pelo fato de Laura ter dito a ele que fosse ao psicólogo cuidar da fragilidade.

\section{Infra-Valoração}

Insegurança

Mal

\section{Medo}

Não Querer / Desamor

\begin{tabular}{ll} 
& rer ao outro, não amá-lo etc. \\
\hline Preocupação & $\begin{array}{l}\text { Preocupação, agonia, incômodo, } \\
\text { nervosismo, inquietação etc. }\end{array}$
\end{tabular}

Covardia, medo, pânico etc.

Detestada, aborrecimento, não querer ao outro, não amá-lo etc.

\section{Indecisão, dúvidas, insegurança etc. Bruno sente-se muito inseguro.}

Quando os sentimentos não são específicos.
Suponho que se sentirá mal por Laura ter lhe dito que fosse ao psicólogo e também por pensar que nunca se acertarão.

Eu acho que tem medo que a relação se acabe.
Pouco querida, porque ele não se importa com o que ela quer.

Sente-se preocupada e inquieta porque nunca sabe o que Bruno fará... Bruno tem uma personalidade muito fechada e não deixa ninguém descobrir como ele realmente é.

Laura sente-se oprimida, parece que se opor a ela e conseguir que prevaleça o que ele quer faz com que Bruno se sinta superior.

Não sei...acho que quem está mais enrolada sobre o assunto é a Laura. 
na tomada de decisões daqueles participantes que aplicaram esse modelo. Vejamos dois exemplos de respostas que ilustram o Modelo 1:

Eu simplesmente chegaria nele e diria que não quero mais nada com ele, que ele está me tratando como um "tapete", que pisa, pisa e pisa e não fala nada. Que eu não aguento mais. Para ele procurar outra trouxa, que a minha paciência chegou ao limite!... E detalhe: não olharia mais na cara dele. Faria isso porque acho que a mulher tem que se valorizar... $(12 \mathrm{a}, \mathrm{M})^{4}$

Terminaria imediatamente com ele, pois não vale a pena ter uma pessoa dessas como namorado... afinal ela foi empurrada e maltratada por ele de propósito! (16a, M)

Como imaginam o agressor. A diversidade de pensamentos e sentimentos identificados nesse modelo configura duas imagens diferentes do agressor. A primeira delas traz um "Bruno" que acredita no domínio exercido sobre sua namorada e, mais ainda, que seu comportamento se dá pela sua necessidade de autoafirmação. Esse tipo de pensamento vincula-se a diferentes modalidades afetivas: em alguns casos provoca ao protagonista bem-estar e em outros lhe causa mal pela imagem (negativa) que pode passar para sua namorada. Vejamos alguns exemplos:

O Bruno pensa que ele deve tratar as garotas como trata os garotos (amigos) e que ele sempre vai estar bem e "acima" de Laura, achando que os gostos dela, opiniões e sentimentos são o de menos para ele e que ela vai estar sempre disposta a concordar com tudo o que ele fala e faz. (12a, M)

Muito mal, pior ainda que a Laura por ela estar mal. Ele tem carinho por ela, mas não consegue se controlar. (16a, M)

Na segunda imagem aparece um "Bruno" com forte capacidade de negar os fatos ou, no mínimo, sua responsabilidade sobre eles, o que lhe permite experimentar sentimentos agradáveis diante da situação vivida. Alguns dos participantes que imaginaram o protagonista com tais características foram capazes, também, de vê-lo como uma pessoa "azarada" e/ ou "infeliz" pelo que sua namorada - que nesse cenário é a "responsável" pelo conflito - lhe faz. Com isso podemos inferir que, na organização dada a esse modelo, a violência identificada no momento de elaborar a estratégia de resolução é compatível com um agressor cujos estados internos lhe colocam à margem do maltrato. Vejamos um exemplo:

Bruno pensa que em toda relação acontece isso e que não tem nada de anormal...afinal todo mundo briga...todo mundo fica com raiva...não tem nada de mais...e no final tudo se resolve. (16a, M)

Como imaginam a vítima. A imagem de Laura é trazida, por todos os participantes que aplicaram esse modelo, como alguém que experimenta, a partir do comportamento de seu namorado, sentimentos negativos como tristeza, solidão,

$4 \quad$ A referência utilizada obedece ao seguinte critério: idade (12a, 14a ou 16a) e sexo (F ou M). impotência, inferioridade etc. Tais sentimentos não impedem que ela reafirme seu amor pelo namorado:

Laura sente-se impotente e triste com tudo o que está passando com Bruno, pois ela gosta muito dele. (12a, F)

Sente muita dor por Bruno não reconhecer o amor dela. (14a, $\mathrm{M})$

A atribuição de pensamentos e sentimentos configura duas imagens diferentes para a protagonista. Na primeira delas, Laura defende-se da agressão sofrida de duas maneiras: valorando negativamente a conduta de Bruno ou simplesmente afastando-se dele. Eis respostas que as ilustram:

Laura sente-se ofendida por Bruno porque ele nunca entende os seus motivos, nunca está de acordo com ela. (16a, F)

Sente-se muito mal e com isso ela acabará deixando Bruno. $(14 a, M)$

Na segunda imagem aparece uma Laura que se esforça para manter a relação, e o faz de duas maneiras distintas: questionando-se sobre os acontecimentos (que para ela são incompreensíveis) ou mantendo as coisas como estão. A seguir duas respostas que ilustram essa imagem da protagonista:

Sente-se mal porque não consegue entender o que acontece... por que Bruno age daquela maneira e com isso se pergunta que atitude deveria tomar para consertar as coisas. (12a, F)

Sente-se intimidada pelos atos de Bruno...sente-se desprezada, mas não consegue controlar a situação e acaba fazendo o que não desejava fazer, que é aguentar o Bruno para tentar manter as coisas bem... (12a, F)

Tais pensamentos, dentro de um modelo que, como descrevemos, propõe a ruptura como estratégia de resolução para o conflito, dá visibilidade às defasagens intrapessoais e às dificuldades internas para finalizar uma relação.

Estratégia de resolução e estrutura interativa. As características próprias desse primeiro modelo - identificação da violência, seu significado como maltrato e a decisão de romper o vínculo afetivo - aparecem dentro de uma dinâmica estruturada por estados internos antagônicos. Os pensamentos e sentimentos atribuídos a cada um dos protagonistas configuram uma relação de "confronto" entre eles: enquanto o agressor é visto como uma pessoa que deseja e/ou necessita dominar sua namorada para demonstrar segurança e autoridade (autoafirmação), a vítima é vista como uma pessoa que não admite a violência e que está determinada a separar-se do namorado.

Um aspecto comum a todos os participantes que aplicaram esse modelo foi o fato de terem identificado uma relação de "oposição" entre os protagonistas. Tal aspecto abre as portas, também, para a diversidade de representações que, nesse caso, dá-se numa maior ou menor amplitude de tal "oposição": alguns participantes a projetam na atribuição de pensamentos e sentimentos, outros o fazem somente na atribuição dos pensamentos e outros a expres- 
sam somente no âmbito afetivo, ou seja, na atribuição de sentimentos.

\section{Modelo 2: desavenças e possível ruptura}

Este modelo diferencia-se do anterior especialmente pelo significado atribuído ao comportamento violento de Bruno que, nesse caso, é visto como susceptível de mudanças. Consequentemente, apesar de não acreditarem muito em tais mudanças, decidem dar ao agressor uma oportunidade para que ele mude sua conduta. Com isso analisam a situação sugerindo que Laura converse com Bruno e, caso a situação não se resolva, rompa a relação. Nesse modelo, o confronto entre os protagonistas não parece ser algo irreversível, o que faz com que os participantes que o aplicam acreditem que uma conversa ou ajuda de terceiros podem ser alternativas para erradicar a violência e encontrar novamente o equilíbrio na relação. Vejamos dois exemplos de respostas que ilustram o Modelo 2:

Eu conversaria com o Bruno. Tentaria descobrir a razão de tudo isso; se ele realmente gosta de mim e por que está tão inseguro. Se ele não revelasse nada eu pediria um tempo, ficaria um pouco distante dele para ele pensar melhor em tudo o que aconteceu com a gente, depois eu voltaria a falar com ele e quem sabe até sair também, mas só se ele conversasse direito comigo e me explicasse o porquê de tudo isso. (14a, F)

Se eu estivesse no lugar da Laura conversaria com o Bruno sobre tudo o que está acontecendo e deixaria claro que a minha vida não é viver só para ele. Se nada mudasse terminaria o relacionamento numa boa e continuaria só na amizade. Só assim eu poderia ter mais liberdade. (16a, F)

\section{Modelo 3: diálogo e manter a relação}

Neste modelo, as agressões sofridas por Laura ou são menosprezadas ou recebem o significado de problemas ou dificuldades de Bruno, como pode ser ilustrado nos exemplos que se seguem:

Eu conversaria com Bruno sobre nossos problemas, pois em um relacionamento é importante que haja sinceridade e clareza de ambas as partes. Eu faria isso pois deve existir compreensão e perdão de ambas as partes. (16a, $\mathrm{F})$

Eu tentaria conversar com ele, procurando entendê-lo...procurando entender o momento que ele está passando. (14a, F)

Essa mudança de interpretação do conflito vem acompanhada de uma imagem diferente de Bruno, de Laura e da relação que os une. Os participantes que interpretaram o texto com esse modelo parecem não ter "lido" as agressões que Laura sofreu. Para eles, a situação retrata pequenos problemas entre duas pessoas cujos estados internos permitem sua superação. Daí a razão pela qual sugerem como estratégia de resolução conversar e manter a relação.

\section{Modelo 4: aceitação silenciosa e manter a relação}

O elemento organizador deste modelo é o comportamento de Bruno que é visto, por ele e por Laura, como inevitável. Como consequência, sugerem que a vítima tenha uma postura passiva diante da situação, quer seja porque ela gosta de Bruno, quer seja porque o considera mais em conflito do que violento:

Eu não faria nada porque eu quero ele. (12a, F)

Esperaria ele superar aquele momento. (12a, F)

\section{Modelo 5: interesses do agressor em manter a relação}

Estratégia de resolução. A problemática interna do protagonista, seus desejos, interesses e necessidades são os elementos ao redor dos quais giram os demais. A importância dada aos conflitos pessoais de Bruno faz com que ele seja visto como uma pessoa em conflito (e não violenta) e que as agressões sofridas por Laura tornem-se praticamente invisíveis. Com isso, os participantes que aplicaram o Modelo 5 sugerem que Laura está disposta a ajudar ao seu namorado e a sacrificar seus interesses pessoais em benefício dele. Vejamos um exemplo dessa organização:

Tentaria conversar com a pessoa, esclarecer o fato e ajudar a ele. Afinal, numa relação sempre tem alguém que deve ceder e aguentar...senão tudo fica mais dificil. (14a, F)

A motivação de Laura para socorrer ao agressor ocupa lugar central em muitas respostas desse modelo. Seu desejo em ajudá-lo é assim explicitado:

Eu ajudaria o garoto pois é dificil passar por problemas e não ser ajudado. Eu fico imaginando como ele está se sentindo inseguro e o que eu poderia fazer para cuidar dele, para fazer com ele se sinta bem. (16a, F)

Além de sugerirem ajuda ao Bruno e sacrifício por ele, identificamos algumas respostas que, de alguma maneira, parecem culpar Laura pela situação de Bruno. Vejamos um exemplo:

Eu acho que quando um não quer dois não brigam. Também é preciso saber o que Laura fez para que as coisas chegassem a esse ponto. E se ela quiser consertar as coisas ela também vai ter que mudar. (16a, F)

Como imaginam o agressor. Os sentimentos do agressor revelam a imagem de um rapaz inseguro e frágil. Sua problemática interna é utilizada como justificativa para seus atos, livrando-o de qualquer responsabilidade e/ou culpa:

O Bruno sente-se inseguro quanto ao amor que ela sente por ele pelo fato de ela viver rodeada de amigos. (14a, F) 
Tabela 6. Distribuição dos participantes em função das idades, sexo e modelos organizadores.

\begin{tabular}{|c|c|c|c|c|c|c|c|c|c|c|c|c|c|c|c|c|c|c|c|c|c|}
\hline \multirow{2}{*}{$\begin{array}{l}\text { Modelos } \\
\text { Idade }\end{array}$} & \multicolumn{4}{|c|}{ Modelo 1} & \multicolumn{4}{|c|}{ Modelo 2} & \multicolumn{4}{|c|}{ Modelo 3} & \multicolumn{4}{|c|}{ Modelo 4} & \multicolumn{4}{|c|}{ Modelo 5} & \multirow{2}{*}{ Total } \\
\hline & 12 & 14 & 16 & $\mathrm{~T}$ & 12 & 14 & 16 & $\mathrm{~T}$ & 12 & 14 & 16 & $\mathrm{~T}$ & 12 & 14 & 16 & $\mathrm{~T}$ & 12 & 14 & 16 & $\mathrm{~T}$ & \\
\hline Feminino & 07 & 06 & 05 & 18 & - & 05 & 07 & 12 & 07 & 02 & 07 & 16 & 03 & 02 & - & 05 & 03 & 04 & 02 & 09 & 60 \\
\hline Masculino & 14 & 10 & 08 & 32 & 04 & 03 & 03 & 10 & - & 04 & 04 & 08 & - & 02 & 03 & 05 & 02 & 02 & 01 & 05 & 60 \\
\hline TOTAL & 21 & 16 & 13 & 50 & 04 & 08 & 10 & 22 & 07 & 06 & 11 & 24 & 03 & 04 & 03 & 10 & 05 & 06 & 03 & 14 & 120 \\
\hline
\end{tabular}

Nota - Modelo 1: maltrato e ruptura; Modelo 2: desavenças e possível ruptura; Modelo 3: diálogo e manter a relação; Modelo 4: aceitação silenciosa e manter a relação; Modelo 5: interesse do agressor e manter a relação.

Para além desse revestimento afetivo, alguns participantes trouxeram a imagem de um agressor cuja "impotência" cognitiva coloca Laura na difícil situação de decidir o que fazer:

Bruno gostaria de demonstrar que não era tão frágil e que poderia tomar as decisões pelos dois...mas ele não sabe o que fazer de verdade...nem como fazer. (14a, M)

Como imaginam a vítima. Diante do Bruno "criado" para esse modelo, os participantes que o aplicaram imaginam uma Laura triste, confusa e, apesar de não saber como ajudar ao namorado, está disposta a fazê-lo. Eis um exemplo que ilustra bem o Modelo 5:

A Laura se sente responsável e confusa diante da situação. Ela sofre muito com tudo o que acontece. E nem pensa em terminar o relacionamento com ele, mas em ajudá-lo a resolver os seus problemas, mas ela não sabe o que fazer. (16a, F)

Estratégia de resolução e estrutura interativa. Uma característica própria do Modelo 5 é o fato de a violência só ser mencionada quando os participantes referem-se aos estados internos dos protagonistas, sendo ignorada no momento em que sugerem as estratégias de resolução. A dinâmica relacional desse modelo implica uma "complementaridade" entre amor e domínio que se manifesta tanto nas estratégias de resolução como nos estados internos - pensamentos e sentimentos - atribuídos aos protagonistas.

\section{$3^{0}$ Passo: Análise quantitativa}

Apesar de nosso propósito para o presente estudo ser basicamente realizar uma exploração qualitativa das representações mentais sobre a violência, parece-nos também oportuno apresentar a distribuição dos participantes em função dos modelos organizadores aplicados e das variáveis idade e sexo. Vale ressaltar que todos os protocolos foram codificados por três pesquisadoras e, em caso de desacordo (14\%), chegou-se por consenso a uma decisão unitária.
Os resultados obtidos em função das idades e sexo dos participantes e dos modelos por eles aplicados encontram-se na Tabela 6 , que se segue.

Na Tabela 6 é possível verificar que 50 participantes (41,7\% deles) identificam claramente a violência sofrida pela protagonista e a veem como maltrato (Modelo 1), decaindo de 21 participantes $(52,5 \%)$ aos 12 anos para 16 participantes $(40 \%)$ aos 14 anos e 13 participantes $(32,5 \%)$ aos 16 anos. O número de homens que o fazem é maior que o de mulheres: 32 homens ( $53,5 \%$ deles) e 18 mulheres ( $18 \%$ delas). Ressalta-se, ainda, a diferença encontrada entre os participantes de 12 anos: 14 homens e sete mulheres dessa idade aplicaram o referido modelo.

Aqueles que acreditam que o comportamento violento do protagonista é susceptível de mudanças (Modelo 2) somam 22 participantes $(18,5 \%$ da amostra $)$ e, ao contrário do que acontece no primeiro modelo, verifica-se maior frequência entre os participantes de 16 anos (10 deles - 25\%) do que entre os de 14 anos (oito deles - 20\%) ou 12 anos (quatro deles - 10\%). Nesse modelo verifica-se, também, 12 respostas femininas $(20 \%)$ e 10 respostas masculinas $(16,7 \%)$.

Os modelos nos quais as agressões sofridas pela protagonista parecem não ser consideradas (Modelos 3, 4 e 5) somam 48 participantes ( $40 \%$ do total da amostra). Aqueles que encaram o conflito como pequenos problemas de uma relação e sugerem que Laura converse com Bruno e mantenha a relação (Modelo 3) somam 24 participantes (20\% da amostra), sendo mais frequente entre aqueles de 16 anos (11 deles - 27,5\%) do que entre os de 14 anos (seis deles - 15\%) ou de 12 anos (sete deles - 17,5\%). O número de mulheres que aplicam o Modelo 3 é o dobro do de homens: 16 mulheres $(26,7 \%)$ e oito homens ( $13,3 \%$ deles).

Aceitar silenciosamente a situação e manter a relação (Modelo 4) foi a estratégia sugerida por 10 participantes (8,3\% da amostra), com as seguintes diferenças entre as idades: três participantes de 12 anos (7,5\% deles), quatro participantes de 14 anos ( $10 \%$ deles) e três participantes de 16 anos (7,5\% deles), não havendo nenhuma diferença entre as amostras feminina e masculina (em cada uma delas identificamos cinco respostas). 
O Modelo 5, cuja organização está centrada nos interesses do agressor, foi aplicado por 14 participantes $(11,7 \%$ da amostra). Verifica-se maior frequência de respostas entre os participantes de 12 e 14 anos (cinco e seis deles - 12,5\% e $15 \%$, respectivamente) do que entre os de 16 anos (três deles - 7,5\%). O número de mulheres é maior que o de homens: nove mulheres ( $15 \%$ delas) e cinco homens ( $8,3 \%$ deles $)$.

\section{Discussão}

Os resultados encontrados permitiram-nos constatar a riqueza e a diversidade das representações subjetivas com que cada indivíduo posiciona-se diante da violência contra a mulher. Um mesmo episódio de violência foi interpretado diferentemente por cada um dos participantes, dependendo da perspectiva na qual a analisaram: se "pragmática" (estratégias de resolução para o conflito) ou "intimista" (atribuições de pensamentos e sentimentos aos protagonistas).

Apesar da diversidade (e singularidade) de respostas obtidas, identificamos cinco diferentes modelos organizadores com os quais os participantes analisaram o conflito em questão. Tais modelos refletem formas diferentes de posicionar-se diante da violência contra a mulher. Quando a violência é identificada no momento de propor planos de ação (Modelos 1 e 2), os participantes imaginam uma relação de oposição entre os protagonistas e defendem que a ruptura é a melhor solução para o conflito. Quando a violência é reconhecida apenas na atribuição de pensamentos e sentimentos (Modelos 3, 4 e 5), defendem que os protagonistas devem manter a relação e sugerem que entre eles existe uma dinâmica de complementaridade.

Os Modelos 1 e 2 trazem uma dinâmica na qual a identificação e o rechaço da violência parecem permitir aos participantes imaginarem o agressor como uma pessoa que quer dominar sua parceira. Esta, por sua vez, é vista como uma pessoa que não está disposta a ser submissa a ele. Para além de reconhecer as estruturas afetivas de domínio e submissão, nesses modelos os participantes parecem não aceitá-las, o que lhes leva a propor a ruptura como estratégia de resolução para o conflito.

Nos outros modelos - Modelos 3, 4 e 5-, os participantes parecem negar - total ou parcialmente -, alguns dados do conflito. As agressões sofridas pela vítima, por exemplo, são praticamente ignoradas no momento em que elaboram as estratégias de resolução, e quando as consideram - na atribuição de pensamentos e sentimentos -, parecem dar mais importância à fragilidade e insegurança do agressor (e aos cuidados que ele requer) do que aos efeitos de suas violentas ações sobre a vítima.

A percepção do agressor como uma pessoa frágil, triste e insegura parece abrir as portas para a imagem de uma vítima que, a fim de ajudá-lo, aceita ser dominada e/ou submissa. O desejo de manter uma relação amorosa com o agressor está apoiado na ideia de que a pessoa que atua violentamente o faz por uma problemática interna, o que, de alguma maneira, parece justificar seu comportamento. Isso nos aproxima da hipótese que levantamos inicialmente: que o desenvolvimento anômalo da ética da justiça pode levar ao narcisismo e à solidão; e que o desenvolvimento anômalo da ética do cuidado pode levar à perda do controle da própria existência.

Ora, se a solidariedade tem, em princípio, um valor adaptativo (a fim de favorecer o outro), ela deixa de tê-lo quando é exercida em benefício do agressor e em detrimento do respeito e das necessidades de quem sofre a violência. Nesse caso, passa a ser um contravalor que se sustenta nos processos inadaptáveis complementares: a criação de um agressor narcisista e solitário e de uma vítima sofredora.

Nesse sentido, a ideia explicitada por parte dos participantes de nosso estudo - de que a violência sofrida pela mulher pode ser evitada se ela ajudar seu namorado - parece ser um caminho tortuoso, no qual um modelo de amor unilateral (que a mulher é quem deve amar e cuidar) e a ética do cuidado (em nossa opinião mal compreendida) parecem desvelar uma cumplicidade entre quem exerce e quem se submete ao poder. Um caminho que nos distancia da relação estabelecida por Benhabib (1992) - mencionada no início deste texto -, entre identidade, ética e direitos humanos, e que pressupõe integrar autonomia e solidariedade, bem como justiça e cuidado.

Mas não podemos incorrer no risco de reduzirmos a problemática da violência contra a mulher a um julgamento moral. A ajuda ao agressor sugerida pelos jovens neste estudo reflete, também, uma articulação confusa e desconexa entre diferentes desejos: evitar a violência; defender a relação por qualquer preço (inclusive pela dignidade e bem-estar da vítima); compensar a fragilidade do agressor dando-lhe uma segurança que não possui.

Tais desejos parecem-nos consoantes com resultados encontrados por Narvaz e Koller (2006b), em estudo de caso com uma mulher-mãe, vítima de várias formas de violência em sua história de vida. Em suas análises, as autoras evidenciaram como fator de submissão dessa mulher a relações violentas, seu desejo de viver um modelo hegemônico de família. Apesar de não ter vivido efetivamente um modelo patriarcal de família, tal modelo influenciou sobremaneira as representações de família da referida mulher, a ponto de levá-la a suportar e, de certa forma, "naturalizar" a violência que sofreu.

Nossos resultados apontam que o modelo no qual a violência foi explicitamente identificada e significada como maltrato (Modelo 1) foi aplicado mais pelos homens que pelas mulheres. Um pouco mais da metade da amostra masculina recorreu a esse modelo para analisar o conflito que lhe foi apresentado, enquanto um percentual bem menor da amostra feminina o fez. Interessante notar que esse mesmo modelo foi aplicado mais pelos jovens de 12 anos do que pelos de 14 ou 16. O fato é que nossos resultados mostram que o reconhecimento da violência se dá mais entre os homens do que entre as mulheres; e mais entre os mais novos do que entre os mais velhos. Tais dados parecem sinalizar, como nos advertiu Traverso-Yépez e Pinheiro (2005), um processo de naturalização e perpetuação da violência de gênero que se dá, entre outras coisas, pela reprodução, por parte das próprias mulheres, de padrões sexistas de socialização. Em suma, a partir de nosso estudo podemos ponderar que: (a) a invisibilidade da violência resiste às tentativas de delimitar e relacionar adequadamente as distintas vertentes do conflito. Dito de outra forma, é mais difícil analisar e combater aquilo que 
permanece "velado", "obscuro" ou "confuso" do que aquilo que é explicitamente reconhecido. Foi o que identificamos ao analisar as representações de jovens sobre a violência contra a mulher; (b) os processos de socialização em nossa cultura se dão sob um imaginário coletivo de domínio dos homens sobre as mulheres. Uma ordem social que divide e caracteriza os sujeitos em função de seu grau de poder e, mais ainda, que atribui a cada grupo aquelas características psíquicas necessárias para que cumpram "suas" tarefas sociais.

Apesar dessas ponderações, não podemos perder de vista a diversidade e singularidade das representações que obtivemos neste estudo. Elas são prova da complexidade que envolve a temática da violência contra a mulher e da necessidade de enveredarmos por estudos que promovam uma maior integração entre as dimensões afetivas, cognitivas e sociais presentes no psiquismo humano.

\section{Referências}

Affonso, S. (2008). Estados emocionais e os Modelos Organizadores do Pensamento: um estudo sobre violência de gênero. Tese de Doutorado, Universidade Estadual de Campinas, Campinas.

Benhabib, S. (1992). Una revisión del debate sobre las mujeres y la teoría moral. Isegoría, 6, 37-63.

Benjamín, J. (1996). Los lazos del amor. Barcelona: Paidós.

Benjamín, J. (1997). Sujetos iguales, objetos de amor. Ensayos sobre el reconocimiento y la diferencia sexual. Barcelona: Paidós.

Bravo, M. (1994). Incesto y violación. Chile: Academia.

Bush, R., \& Folger, J. (1994). The promise of mediation: Responding to conflict through empowerment and recognition. San Francisco: Jossey-Bass.

Corsi, J. (1997). Violencia familiar: Una mirada interdisciplinaria sobre un grave problema social. Buenos Aires: Paidós.

Corsi, J. (org). (2003). Maltrato y abuso en el ambito doméstico. Buenos Aires: Paidós.

Del Barrio, C., Almeida, A., Van der Meulen, K., Barrios, A., \& Gutiérrez, H. (2003). Representaciones acerca del maltrato entre iguales, atribuciones emocionales y percepción de estrategias de cambio a partir de un instrumento narrativo: SCAN-Byllying. Infancia y Aprendizaje, 26, 63-78.

Ferrer, V. A. \& Bosch, E. (2003). Algunas consideraciones generales sobre el maltrato de mujeres en la actualidad. Anuario de Psicología, 34, 203-213.

Giddens, A. (1993). A transformação da intimidade: sexualidade, amor e erotismo nas sociedades modernas. São Paulo: UNESP.
Gilligan, C. (1982). In a different voice: Psychological theory and women's developmental. Cambridge: Harvard University.

Lima, D. C., Buchele, F., \& Clímaco, D. A. (2008). Homens, gênero e violência contra a mulher. Saúde e Sociedade, 17, 69-81.

Machado, L. Z. (2004). Masculinidades e violências: gênero e mal estar na sociedade contemporânea. Em M. R. Schpun (Org.), Masculinidades. (pp. 35-78). São Paulo: Boitempo.

Marimón, M., Sastre, G., Bovet, M., \& Leal, A. (2000). Conhecimento e mudança: os modelos organizadores na construção do conhecimento (A. Venite, Trad.). São Paulo: Moderna (Trabalho original publicado em 1988)

Martins, S. M. P. (2008). Cultura e gênero: um estudo na perspectiva dos Modelos Organizadores do Pensamento. Tese de Doutorado, Universidade Estadual de Campinas, Campinas.

Narvaz, M. G., \& Koller, S. H. (2006a). Mulheres vítimas de violência doméstica: compreendendo subjetividades assujeitadas. Psico (RS), 37, 7-13.

Narvaz, M. G., \& Koller, S. H. (2006b). A concepção de família de uma mulher-mãe vítima de incesto. Psicologia: Reflexão $e$ Crítica, 19, 395-406.

Nascimento, M. (2004). (Re)pensando as "masculinidades adolescentes": homens, jovens, gênero e saúde. Em A. P. Uziel, L. F. Rios \& R. G. Parker (Orgs.), Construções da sexualidade: gênero, identidade e comportamento em tempos de AIDS (pp. 105-113). Rio de Janeiro: Pallas/IMS/ABIA.

Noam, G. C., \& Fisher, K. W. (1996). Development and vulnerability in close relationships. New Jersey: Lawrence Erlbaum.

Sastre, G., Arantes, V., \& González, A. (2007). Violencia contra las mujeres: significados cognitivos y afectivos en las representaciones mentales de adolescentes. Infancia y Aprendizaje, 30, 197-214.

Taquette, S. R., Ruzany, M. H., Meirelles, Z., \& Ricardo, I. (2003). Relacionamento violento na adolescência e risco de DST/ AIDS. Caderno Saúde Pública, 19, 1437-1444.

Traverso-Yépez, M. \& Pinheiro, V. (2005). Socialização de gênero e adolescência. Estudos Feministas (Florianópolis), 13, 147-162.

Velázquez, S. (2003). Violencias cotidianas, violencia de género. Barcelona: Paidós. 


\section{APÊNDICE}

\section{DIÁRIO DE LAURA}

Este ano eu gostei muito de uma amiga minha ter me convidado para compor a música de uma peça teatral que ela mesma escreveu. A verdade é que eu gostei mesmo foi da minha amiga ter confiado em mim.

A música me ajuda... É uma terapia você se colocar à frente do piano e ver o que sai, tocar, criar e deixar a energia sair... Depois você descansa e fica feliz! Lembrar das coisas boas vale mais que recordar as ruins, mas... Acho que os amigos, a família, o trabalho, os estudos... Tudo em geral vai indo bem.

Encontrar o equilibrio, mantê-lo e sentir-se bem por dentro... Embora pareça um anúncio de iogurte, é o mais difícil e também a mais alegre das recompensas.

Enfim, as coisas do dia-a-dia podem ser boas ou ruins, depende de como você olha para elas. Se você faz um esforço e as vê especiais, te dá alegria e você é feliz.

Algumas vezes me pergunto: é tão difícil ser feliz?; para todos a felicidade é a mesma coisa que para mim?; dentro da felicidade há sempre um pouco de infelicidade?

Agora eu estou preocupada. Há alguns meses eu saio com um menino, Bruno, que é um pouco mais velho que eu. Nós somos amigos e eu gosto muito dele e, embora ele tenha muitas inseguranças, é inteligente e simpático.

Quando eu comecei a sair com ele eu não tinha certeza se ele realmente gostava de mim. Eu disse para ele ir a um psicólogo por causa de sua insegurança, e ele não levou a mal, mas eu acho que ele pensa que eu o acho frágil e essas coisas, e é assim... Às vezes eu o vejo um pouco frágil mas ele me agrada e é realmente um amigo.

O problema é que muitas vezes, quando eu faço alguma sugestão, o Bruno diz o contrário. Por exemplo, se eu quero ir para o cinema, ele diz que quer tomar alguma coisa e conversar; mas se eu quero tomar alguma coisa e conversar, o Bruno pergunta por que não vamos ao cinema. No princípio eu não percebi isto. Agora eu sei que é assim, que quase sempre ele é do contra.

Um dia eu propus que fôssemos para a casa de umas amigas que haviam alugado um filme desses que nós gostamos, e passar a tarde lá. O Bruno disse que estava com mais vontade de dar um passeio e ir tomar alguma coisa. Eu me aborreci, já estava cansada... Sempre que eu propunha alguma coisa ele não estava de acordo.

Nós saímos de mãos dadas e então eu notei que o Bruno me empurrou para cima de uma árvore. Eu tropecei e caí.

Enquanto Bruno me ajudava a levantar, ele só conseguia me dizer que eu sempre andava distraída, que eu era um desastre e que eu sempre caía. A atitude dele me magoou muito e ainda mais porque eu sabia que ele tinha me empurrado contra a árvore.

Eu fiquei tão triste que o Bruno não sabia o que fazer para me agradar. Na verdade, quando eu vi todos os seus esforços e os cuidados que estava tendo comigo, até me esqueci da minha dor. Finalmente nós fomos para o cinema e ficamos muito bem juntos.

Desde então eu via o Bruno tranquilo e muito mais seguro do que antes. Ele me disse que eu sou muito importante para ele.

Eu quase tinha esquecido do rolo da árvore e estava muito confiante. Por isto me doeu o que aconteceu hoje. Tudo começou quando eu disse que este fim de semana eu não poderei sair com ele porque tenho que estudar para uma prova. Eu ainda ouço os seus berros, insultos, e sinto perfeitamente o forte empurrão que ele me deu.

Dessa vez eu não caí, mas foi pior. Eu não sei o que fazer; eu não entendo como ele se atreve a me dizer coisas tão desagradáveis, não sei por que me empurra. Eu me pergunto se isso é alguma coisa que sempre vai acontecer entre nós.

A verdade é que eu não sei o que fazer. Eu gosto do Bruno, eu gosto da música e eu gosto de estar com os meus amigos. Mas às vezes eu fico preocupada com o Bruno. Eu me pergunto se isso é alguma coisa que sempre vai acontecer entre nós. 